\title{
Effects of dexamethasone on the glucogenic capacity of fetal, pregnant, and non-pregnant adult sheep
}

\author{
K L Franko, D A Giussani, A J Forhead and A L Fowden \\ Department of Physiology, Development and Neuroscience, University of Cambridge, Downing Street, Cambridge CB2 3EG, UK \\ (Requests for offprints should be addressed to A L Fowden; Email: alf1000@cam.ac.uk)
}

\begin{abstract}
Fetal glucocorticoids have an important role in the prepartum maturation of physiological systems essential for neonatal survival such as glucogenesis. Consequently, in clinical practice, synthetic glucocorticoids, like dexamethasone, are given routinely to pregnant women threatened with pre-term delivery to improve the viability of their infants. However, little is known about the effects of maternal dexamethasone treatment on the glucogenic capacity of either the fetus or mother. This study investigated the effects of dexamethasone treatment using a clinically relevant dose and regime on glycogen deposition and the activities of glucose6-phosphatase (G6Pase) and phosphoenolpyruvate carboxykinase (PEPCK) in the liver and kidney of pregnant ewes and their fetuses, and of non-pregnant ewes. Dexamethasone administration increased the glycogen content of both the fetal and adult liver within $36 \mathrm{~h}$ of beginning treatment. It also

increased G6Pase activity in the liver and kidney of the fetuses but not of their mothers or the non-pregnant ewes. Neither hepatic nor renal PEPCK activity was affected by dexamethasone in any group of animals. These changes in glycogen content and G6Pase activity were accompanied by rises in the plasma glucose and insulin concentrations and by a fall in the plasma cortisol level in the fetus and both groups of adult animals. In addition, dexamethasone treatment raised fetal plasma tri-iodothyronine $\left(T_{3}\right)$ concentrations and reduced maternal levels of plasma $T_{3}$ and thyroxine, but had no effect on thyroid hormone concentrations in the non-pregnant ewes. These findings show that maternal dexamethasone treatment increases the glucogenic capacity of both the mother and fetus and has major implications for glucose availability both before and after birth.

Journal of Endocrinology (2007) 192, 67-73
\end{abstract}

\section{Introduction}

Glucocorticoids have an important role in the pre-partum maturation of tissues essential for neonatal survival, such as the lungs, liver, kidneys, and gut (Liggins 1994). They induce both structural and functional changes in these tissues and activate many of the biochemical processes, which have little or no function in fetal life (Fowden et al. 1998). In all species studied so far, there is an increase in the circulating glucocorticoid concentration in the fetus towards term, which is responsible for maturing key tissues in preparation for extra-uterine life (Fowden \& Forhead 2004). Consequently, in clinical practice, synthetic glucocorticoids, like dexamethasone, are given routinely to pregnant women with threatened pre-term delivery to improve the viability of their infants (NIH Consensus Development Conference 1995). This report advises routine administration of $2-4$ doses of a synthetic glucocorticoid for $48 \mathrm{~h}$ to all the pregnant women at risk of pre-term delivery before 32 weeks of gestation.

At birth, there is a major switch in nutrition from a continuous maternal supply of nutrients via the placenta to a more intermittent supply from the milk via the gut (Trahair \& Sangild 1997). During the period between birth and the onset of nutritive suckling, the neonate depends on its ability to produce nutrients endogenously (Fowden et al. 2001). This requires adequate fuel reserves and functional glucogenic pathways in the neonate. In sheep, both the liver and kidneys produce glucose (Bergman et al. 1974). In liver, glucogenesis occurs by glycogenolysis and gluconeogenesis, whereas in the kidney, it depends primarily on gluconeogenesis because renal glycogen content is very low in both fetal and adult sheep (Shelley 1961, Bergman et al. 1974, Levitsky et al. 1988). During the last $5-10 \%$ of gestation, there are increases in the hepatic glycogen deposition and in the activity of key gluconeogenic enzymes in the fetal liver, which enhance hepatic glucogenic capacity in preparation for the nutritional transition at birth (Shelley 1961, Dawkins 1966, Barnes et al. 1978, Fowden et al. 1993). In sheep (term $145 \pm 2$ days), these increases are dependent on the normal pre-partum increase in fetal plasma cortisol, which begins at about 135 days (Barnes et al. 1978). They can also be induced prematurely by administration of cortisol to fetal sheep before 130 days (Fowden et al. 1993). Maternal treatment with synthetic glucocorticoids during late gestation has been shown to increase hepatic glycogen content in fetal rodents and to elevate the hyperglycemic response to hypoxemic stress in fetal 
sheep (Tye \& Burton 1980, Klepac 1985, Fletcher et al. 2000). However, whether maternal glucocorticoid treatment increases gluconeogenic enzyme activities in the fetal liver remains unknown. Nor is it clear whether this treatment alters hepatic glucogenic capacity in the mother and, thereby, alters the maternal capacity to supply glucose to the fetus. Hence, this study examined the effects of dexamethasone treatment on glycogen deposition and the activities of two rate-limiting gluconeogenic enzymes, glucose-6-phosphatase (G6Pase, EC 3.1.3.9) and phosphoenolpyruvate carboxykinase (PEPCK, EC 3.1.3.11), in the liver and kidney of pregnant ewes and their fetuses during late gestation. These effects were compared with those in the liver and kidney of non-pregnant ewes and related to the circulating concentrations of thyroid hormones, which are known to mediate some of the maturational actions of the glucocorticoids (Fowden et al. 1998).

\section{Materials and Methods}

\section{Animals}

A total of 20 Welsh Mountain ewes between 3 and 4 years of age were used in this study. Ten animals were anoestrus, nonpregnant ewes, while the remainder were time-dated pregnant ewes with single fetuses. All the ewes were kept at grazing until 10 days before the study began. Thereafter, they were fed concentrates $(4 \mathrm{~g} / \mathrm{kg}$ per day, Bearts Ltd, Bury St Edmunds, UK) and hay ad libitum. They had free access to a mineral lick and water at all times.

\section{Experimental procedures}

Beginning at 125 days of gestation (term $145 \pm 2$ days), the pregnant ewes received two i.m. injections of either saline $(2 \mathrm{ml} 0 \cdot 9 \% \mathrm{NaCl} \mathrm{w} / \mathrm{w}, n=5)$ or dexamethasone (12 $\mathrm{mg}$ in $2 \mathrm{ml}$ saline, $0 \cdot 18-0 \cdot 24 \mathrm{mg} / \mathrm{kg}$ ) at $24 \mathrm{~h}$ intervals. The nonpregnant animals received two doses of either saline $(2 \mathrm{ml}$ $0.9 \% \mathrm{w} / \mathrm{w})$ or dexamethasone $(6 \mathrm{mg}$ in $2 \mathrm{ml}$ saline, $0 \cdot 16$ $0 \cdot 25 \mathrm{mg} / \mathrm{kg}, n=5)$ on consecutive days. This dosing regime is identical to the one recommended for use in human clinical practice (NIH Consensus Development Conference 1995) and is known to raise dexamethasone concentrations in fetal and adult ovine plasma for up to $12 \mathrm{~h}$ after administration (Bennett et al. 1999, Jellyman et al. 2005a). Ten hours after the second injection, a blood sample $(10 \mathrm{ml})$ was taken from the jugular vein of all ewes before administration of a lethal dose of anesthetic $(200 \mathrm{mg} / \mathrm{kg}$, sodium pentobarbitone i.v.). In the non-pregnant animals, samples of liver and kidney were collected and frozen immediately in liquid nitrogen. In the pregnant ewes, the fetuses were delivered immediately and a blood sample taken from the umbilical artery $(10 \mathrm{ml})$ before administration of a lethal dose of anesthetic to the fetus (200 mg/kg, sodium pentobarbitone, i.v.). Samples of liver and kidney were then taken from the fetus and mother and frozen in liquid nitrogen. The tissue samples were stored at $-80^{\circ} \mathrm{C}$ until analysis. The blood samples were placed in chilled tubes containing EDTA and then centrifuged at $4{ }^{\circ} \mathrm{C}$. The plasma was stored at $-20{ }^{\circ} \mathrm{C}$ until measurement of plasma glucose and hormone concentrations.

\section{Biochemical analyses}

Plasma concentrations of glucose were measured using a Yellow Springs glucose analyzer (2300 Statplus, Yellow Springs, OH, USA). Plasma concentrations of cortisol, thyroxine $\left(T_{4}\right)$, and tri-iodothyronine $\left(T_{3}\right)$ were determined by RIA validated for use with ovine plasma as described previously (Robinson et al. 1983, Fowden \& Silver 1995). The inter-assay coefficient of variation was $\leq 10 \%$ for all the three assays and minimum detectable concentrations of cortisol, $\mathrm{T}_{4}$, and $\mathrm{T}_{3}$ were $1 \cdot 5,7$, and $0 \cdot 1 \mathrm{ng} / \mathrm{ml}$ respectively. The cortisol antiserum showed no detectable cross reactivity with dexamethasone. The cross reactivity of this antiserum at $50 \%$ binding with other cortisol-related compounds was $0.5 \%$ for cortisone, $2 \cdot 3 \%$ for corticosterone, $0 \cdot 3 \%$ for progesterone, and $4.6 \%$ for deoxycortisol. Dilutions of fetal and maternal plasma produced curves parallel to the standards both in the presence and the absence of dexamethasone. Plasma insulin concentrations were measured by ELISA (Sheep Insulin ELISA, Mercordia, Uppsala, Sweden) using ovine insulin as standards. The minimum detectable concentration of insulin was $0 \cdot 05 \mathrm{ng} / \mathrm{ml}$. The intra-assay coefficient of variation was $3 \cdot 8 \%$. All plasma insulin concentrations were measured in a single assay. All hormone and metabolite concentrations were measured in duplicate.

Tissue activities of G6Pase and PEPCK were measured at $37^{\circ} \mathrm{C}$ as described previously (Fowden et al. 1993). Activity of G6Pase was determined as the rate of phosphate production from glucose-6-phosphate, while PEPCK activity was calculated from the rate of carbon dioxide fixation into oxaloacetate. Tissue protein content was measured using a Lowry protein assay (Forhead et al. 2003). Tissue enzyme activities are expressed as units per gram of protein where one unit of activity is defined as the amount of enzyme required to catalyze the transformation of $1 \mu \mathrm{mol}$ substrate per minute under standard conditions.

Hepatic glycogen content was determined using an enzymatic method modified from Roehrig \& Allred (1974). In brief, tissue homogenates were prepared in cold, deionized water $(100 \mathrm{mg} / \mathrm{ml})$ and frozen at $-80{ }^{\circ} \mathrm{C}$ until analysis. An aliquot of the homogenate $(10 \mathrm{mg})$ was incubated with $5 \mathrm{mM}$ acetate buffer ( $\mathrm{pH} 4 \cdot 5)$, deionized water, and amyloglucosidase enzyme (70 U per tube, Sigma) in a water bath at $55^{\circ} \mathrm{C}$ for $10 \mathrm{~min}$. After incubation, the samples were deproteinized by the addition of equal volumes of zinc sulfate $(0 \cdot 3 \mathrm{M})$ and barium hydroxide $(0.3 \mathrm{M})$. The deproteinized reaction mixture was centrifuged at $2000 \mathrm{~g}$ for $10 \mathrm{~min}$, and the glucose content of the supernatant was measured using a Yellow Springs glucose analyzer (2300 Statplus). Each tissue sample was incubated with and without amyloglucosidase, and the glucose concentration obtained in absence of enzyme 
(tissue blank) was subtracted from the value obtained in the presence of enzyme. Tissue glycogen content was calculated from the molar concentration of glucose and was expressed as mg glucose per gram wet weight of tissue. The minimum detectable level of glycogen was $1.0 \mathrm{mg}$ glucose/g tissue. The intra- and inter-assay coefficients of variation were 2 and $9 \%$ respectively. For all the tissue analyses (G6Pase, PEPCK, glycogen, and protein), two homogenates were made from each tissue and each homogenate was assayed in duplicate.

\section{Statistical analyses}

Means and S.E.M. have been used throughout. Statistical analyses were made using Sigmastat (SPSS Software, Chicago, IL, USA). The significance of differences between groups was assessed using Student's unpaired $t$-test or one-way ANOVA with Tukey's post hoc test for all pairwise comparisons, as appropriate. All data were normally distributed. When plasma cortisol concentrations were at or below the limit of detection of the assay, the minimum detectable value was assigned to the sample for the purposes of statistical analysis.

\section{Results}

\section{Hormone and metabolite concentrations}

Plasma cortisol concentrations were significantly lower in fetal, pregnant, and non-pregnant sheep after dexamethasone treatment than in their saline-treated controls (Table 1). In the non-pregnant ewes, plasma cortisol levels after dexamethasone treatment were below the limit of detection of the assay (Table 1). Plasma cortisol concentrations were significantly higher in pregnant than non-pregnant ewes irrespective of treatment (Table 1). In the dexamethasone-treated pregnant animals, cortisol concentrations were significantly higher in fetal than maternal plasma, whereas in the saline-treated ewes, cortisol levels were significantly higher in maternal than fetal plasma at delivery (Table 1).

Dexamethasone administration also reduced plasma concentrations of the thyroid hormones in pregnant, but not in nonpregnant ewes; mean values of plasma $\mathrm{T}_{4}$ and $\mathrm{T}_{3}$ at delivery were significantly lower in the dexamethasone-treated than salinetreated pregnant ewes, but were unaffected by treatment in the non-pregnant animals (Table 1). In contrast, fetal plasma $\mathrm{T}_{3}$ concentrations were higher in dexamethasone-treated than saline-treated animals (Table 1). Fetal plasma $\mathrm{T}_{4}$ concentrations were unaffected by treatment (Table 1).

Plasma glucose concentrations were significantly higher in dexamethasone-treated than saline-treated fetal, pregnant, and non-pregnant sheep (Table 1). There was no significant difference in the fetal to maternal glucose concentration ratio between the saline-treated $(0 \cdot 20 \pm 0 \cdot 02, n=5)$ and the dexamethasone-treated animals $(0 \cdot 26 \pm 0 \cdot 03, n=5, P>0 \cdot 05)$. Plasma insulin concentrations in the fetal, pregnant, and nonpregnant sheep tended to be higher in dexamethasone-treated than saline-treated animals, but this only reached statistical significance in the fetuses (Table 1). In fetal, pregnant, or nonpregnant sheep, there were no significant differences in hepatic or renal protein content between saline and dexamethasone treatment. Hepatic protein content was significantly lower in fetal than maternal liver, irrespective of treatment (Table 1). Renal protein content in the non-pregnant ewes was also significantly lower than in the pregnant animals following dexamethasone but not saline treatment (Table 1).

Table 1 Mean ( \pm s.E.M.) values of bodyweight, plasma concentrations of glucose, cortisol, $T_{3}, T_{4}$, and insulin, and of protein content in liver and kidneys of fetal, pregnant, and non-pregnant adult sheep after treatment with saline or dexamethasone (Dex)

\begin{tabular}{|c|c|c|c|c|}
\hline & Treatment & Non-pregnant ewe & Pregnant ewe & Fetus \\
\hline \multirow[t]{2}{*}{ Body weight (kg) } & Saline & $34 \cdot 8 \pm 4 \cdot 1^{*}$ & $56 \cdot 0 \pm 3 \cdot 6$ & $3 \cdot 130 \pm 0 \cdot 158^{*}$ \\
\hline & Dex & $29 \cdot 7 \pm 3 \cdot 3^{*}$ & $56 \cdot 2 \pm 2 \cdot 5$ & $3 \cdot 105 \pm 0.063^{*}$ \\
\hline \multirow[t]{2}{*}{ Cortisol (ng/ml) } & Saline & $16 \cdot 6 \pm 2 \cdot 8^{*}$ & $57 \cdot 8 \pm 12 \cdot 4$ & $16 \cdot 1 \pm 2 \cdot 8^{*}$ \\
\hline & Dex & $0 \cdot 4 \pm 0.1^{+}$ & $3 \cdot 2 \pm 0 \cdot 1^{+}$ & $8 \cdot 6 \pm 0.7^{*}$ \\
\hline \multirow{2}{*}{$\mathrm{T}_{3}(\mathrm{ng} / \mathrm{ml})$} & Saline & $1 \cdot 11 \pm 0 \cdot 14$ & $1 \cdot 13 \pm 0 \cdot 08$ & $0 \cdot 28 \pm 0.06^{*}$ \\
\hline & Dex & $1 \cdot 03 \pm 0.25$ & $0.71 \pm 0.08^{+}$ & $0.77 \pm 0.05^{+}$ \\
\hline \multirow{2}{*}{$\mathrm{T}_{4}(\mathrm{ng} / \mathrm{ml})$} & Saline & $47 \cdot 8 \pm 5 \cdot 0$ & $52 \cdot 2 \pm 10 \cdot 7$ & $126 \cdot 3 \pm 22 \cdot 4 *$ \\
\hline & Dex & $44 \cdot 3 \pm 3 \cdot 9$ & $17 \cdot 4 \pm 3 \cdot 6^{+}$ & $132 \cdot 5 \pm 11 \cdot 9^{*}$ \\
\hline \multirow[t]{2}{*}{ Insulin (ng/ml) } & Saline & $0.22 \pm 0.06$ & $0 \cdot 19 \pm 0 \cdot 08$ & $0 \cdot 25 \pm 0 \cdot 05$ \\
\hline & Dex & $0.43 \pm 0.08$ & $0 \cdot 25 \pm 0 \cdot 06$ & $1 \cdot 56 \pm 0 \cdot 28^{*^{+}}$ \\
\hline \multirow[t]{2}{*}{ Glucose $(\mathrm{mmol} / \mathrm{l})$} & Saline & $3 \cdot 89 \pm 0 \cdot 26$ & $3 \cdot 54 \pm 0 \cdot 40$ & $0 \cdot 72 \pm 0 \cdot 11 *$ \\
\hline & Dex & $6 \cdot 01 \pm 0 \cdot 20^{+}$ & $5 \cdot 54 \pm 0.56^{+}$ & $1 \cdot 45 \pm 0.23^{*+}$ \\
\hline \multicolumn{5}{|l|}{ Protein content $(\mathrm{mg} / \mathrm{g})$} \\
\hline \multirow[t]{2}{*}{ Liver } & Saline & $183 \cdot 8 \pm 7 \cdot 9$ & $181 \cdot 5 \pm 4 \cdot 5$ & $131 \cdot 1 \pm 5 \cdot 7^{*}$ \\
\hline & Dex & $146 \cdot 2 \pm 16 \cdot 7$ & $156 \cdot 2 \pm 6 \cdot 8$ & $124 \cdot 2 \pm 4 \cdot 0^{*}$ \\
\hline \multirow[t]{2}{*}{ Kidney } & Saline & $116 \cdot 9 \pm 6 \cdot 8$ & $127 \cdot 8 \pm 7 \cdot 0$ & $126 \cdot 7 \pm 5 \cdot 8$ \\
\hline & Dex & $111 \cdot 5 \pm 2 \cdot 9^{*}$ & $149 \cdot 3 \pm 10 \cdot 0$ & $121 \cdot 8 \pm 5 \cdot 4$ \\
\hline
\end{tabular}

*Significantly different from values in the pregnant ewe $\left(P<0 \cdot 05\right.$, ANOVA); ${ }^{+}$significantly different from values in the corresponding group of saline-treated animals $(P<0 \cdot 05, t$-test $)$. 
Glycogen content and gluconeogenic enzyme activities

Glycogen Dexamethasone administration increased glycogen deposition in the liver of all animals: mean fetal and adult glycogen contents were significantly higher after dexamethasone treatment than in the corresponding saline-treated controls (Fig. 1A). There were no significant differences in hepatic glycogen content between pregnant and nonpregnant ewes after either saline or dexamethasone treatment (Fig. 1A). The glycogen content of the fetal, pregnant, and non-pregnant adult kidney was at or below the level of detection of the assay in all animals, regardless of treatment.

Glucose-6-phosphatase Dexamethasone administration had no effect on G6Pase activity in adult liver: mean activities were similar after saline and dexamethasone treatment in both groups of ewes (Fig. 1B). There was also no significant difference

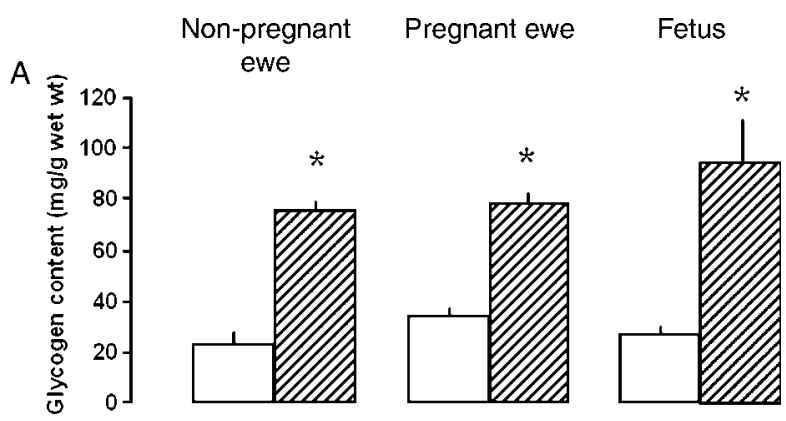

B
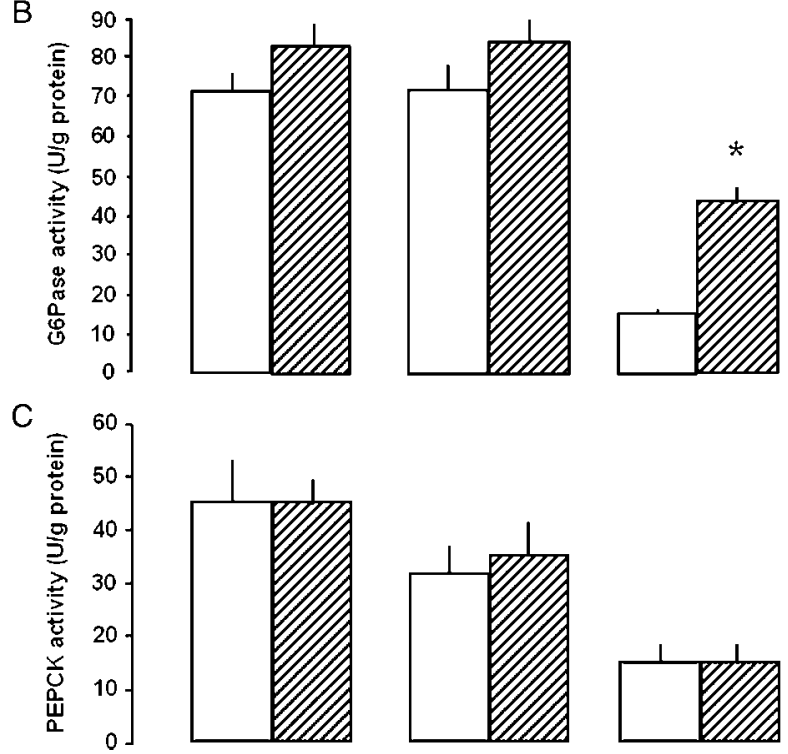

Figure 1 Mean values ( \pm s.E.M.) of (A) glycogen content, (B) glucose-6-phosphatase (G6Pase) activity, and (C) phosphoenolpyruvate carboxykinase (PEPCK) activity in liver from sheep fetuses, pregnant, and non-pregnant ewes treated with saline (open columns) or dexamethasone (filled columns). Details of the doses are given in the text. *Significantly different from the value in corresponding group of saline-treated animals $(P<0 \cdot 05, t$-test $)$. in hepatic G6Pase activity between the pregnant and nonpregnant ewes after either saline or dexamethasone treatment (Fig. 1B). In contrast, G6Pase activity in adult kidney was significantly higher in dexamethasone-treated than salinetreated ewes irrespective of reproductive status (Fig. 2A). Renal G6Pase activity was similar in the saline-treated pregnant and non-pregnant ewes but was significantly greater in the nonpregnant than pregnant ewes after dexamethasone treatment (Fig. 2A, $P<0 \cdot 05$ ). In the fetus, G6Pase activities were significantly higher in the liver and kidney after maternal dexamethasone treatment than in the saline-treated controls (Figs 1B and 2A). Fetal hepatic and renal G6Pase activities were significantly lower than those in the pregnant and the nonpregnant ewes, both after saline and dexamethasone administration (Figs $1 \mathrm{~B}$ and $2 \mathrm{~A}, P<0 \cdot 05$, all cases).

PEPCK Hepatic and renal PEPCK activities were not affected by dexamethasone treatment in either the fetus or the adult (Figs 1C and 2B). Pregnancy per se also had no effect on these enzyme activities (Figs 1C and 2B). Hepatic and renal PEPCK activities in the fetus were significantly lower than those in the adult, regardless of treatment or pregnancy (Figs $1 \mathrm{C}$ and $2 \mathrm{~B}, P<0 \cdot 02$, all cases).
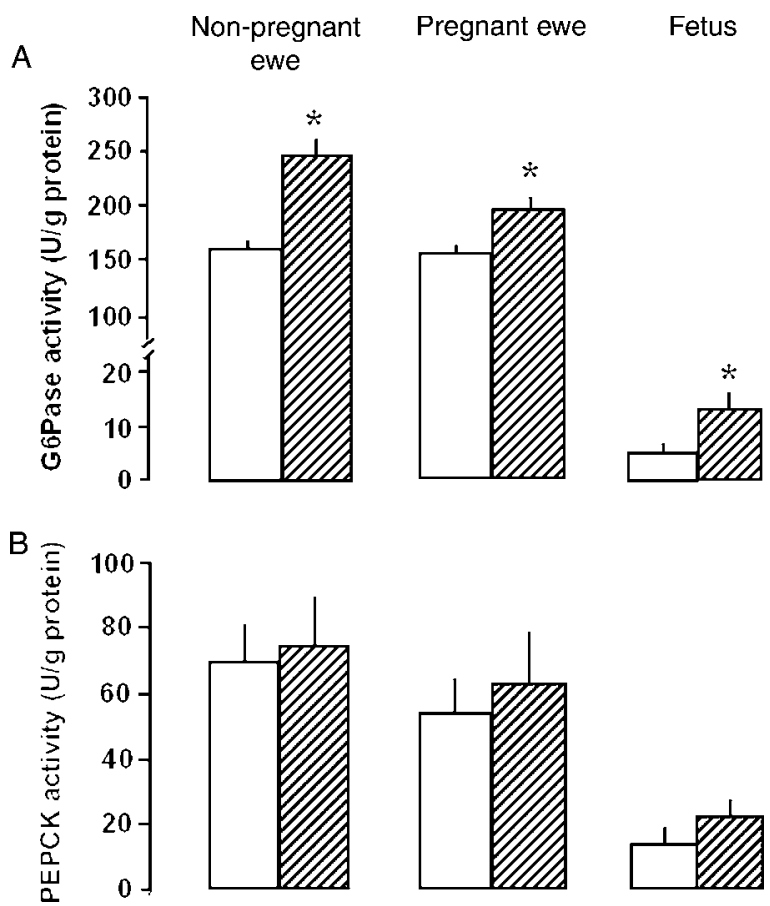

Figure 2 Mean values ( \pm s.E.M.) of (A) glucose-6-phosphatase (G6Pase) activity and (B) phosphoenolpyruvate carboxykinase (PEPCK) activity in kidney from sheep fetuses, pregnant, and nonpregnant ewes treated with saline (open columns) or dexamethasone (filled columns). Details of the doses are given in the text. * Significantly different from the value in corresponding group of saline-treated animals $(P<0 \cdot 05, t$-test $)$. 


\section{Discussion}

The results show that dexamethasone administration to pregnant and non-pregnant ewes increases hepatic glycogen deposition and renal, but not hepatic G6Pase activity in the adult. In contrast, this treatment increased the hepatic glycogen content and the activity of G6Pase in the liver and kidney of the fetuses. Neither renal nor hepatic PEPCK activity was affected by dexamethasone treatment in any of the groups of animals. Administration of dexamethasone therefore increases the hepatic and renal glucogenic capacity in sheep, irrespective of age or reproductive status. In the liver, the effects of shortterm dexamethasone exposure appeared to be primarily on the capacity for glycogenolysis rather than gluconeogenesis.

\section{Dexamethasone and the capacity for glucogenesis}

In the current study, hepatic glycogen content increased twoto threefold within $36 \mathrm{~h}$ of beginning dexamethasone treatment in all groups of animals. Similar increases in fetal hepatic glycogen content have been observed $24 \mathrm{~h}$ after dexamethasone administration to pregnant monkeys, mice, and rats during late gestation (Epstein et al. 1977, Tye \& Burton 1980, Klepac 1985). Previous studies have also shown that infusing cortisol directly into fetal sheep for 5 days increases glycogen deposition and the activities of G6Pase and PEPCK in the fetal liver (Barnes et al. 1978, Fowden et al. 1993). In the current study, maternal dexamethasone treatment had no effect on fetal hepatic PEPCK activity despite a doubling of G6Pase activity in the fetal kidney and liver. These findings indicate that the effects of glucocorticoids in the fetus are tissue specific and may depend on the duration of exposure and/or the degree of mineralocorticoid receptor activation. They also suggest that G6Pase may be more sensitive to short-term dexamethasone exposure than PEPCK. Since hepatic glycogen is the primary source of glucose in the period immediately after birth (Shelley 1961), rapid maturation of the glycogenolytic pathways in response to glucocorticoids would maximize the chances of survival should delivery occur (Fowden et al. 2001).

\section{Dexamethasone and the plasma concentrations of metabolites and hormones}

The increases in hepatic glycogen content and G6Pase induced by dexamethasone in the present study were accompanied by a rise in the glucose level and a fall in the cortisol concentration in the fetus and both groups of adults. The dexamethasone-induced rise in glycemia may be due to insulin antagonism, activation of glucogenesis and/or, in the fetus, increased transplacental glucose transfer in response to the maternal hyperglycemia. Since the fetal to maternal glucose concentration ratio was unaffected by dexamethasone treatment, induction of significant fetal glucogenesis is unlikely in these circumstances, despite the increased glycogen content and G6Pase activity in the fetal liver. In common with previous studies (Bell et al. 1991, Jellyman et al. $2005 b)$, cortisol levels were higher in pregnant than non-pregnant ewes, even when concentrations fell in response to administration of exogenous synthetic glucocorticoids. These observations are consistent with previous suggestions that pregnancy reduces feedback inhibition of the glucocorticoids (Keller-Wood et al. 1988). However, some of the cortisol present in the circulation of the pregnant ewes after dexamethasone treatment may have been derived from the fetus, as fetal cortisol concentrations were higher than maternal values in these animals at delivery.

In the current study, dexamethasone treatment increased plasma $T_{3}$ concentrations in the fetus but reduced plasma concentrations of both $\mathrm{T}_{3}$ and $\mathrm{T}_{4}$ in their mothers. In contrast, thyroid hormone levels were unaffected by dexamethasone administration in the anoestrous, non-pregnant ewes. Similar increases in fetal plasma $T_{3}$ have been observed in human infants after maternal dexamethasone treatment and in fetal sheep infused with cortisol before term (Osathanondh et al. 1978, Thomas et al. 1978, Forhead et al. 2003). Dexamethasone has little effect on plasma $\mathrm{T}_{4}$ and $\mathrm{T}_{3}$ concentrations in pregnant women but reduces these concentrations in men, non-pregnant women, and male rats (DeGroot \& Hoye 1976, Osathanondh et al. 1978, Mitsuma \& Nogimori 1982). These observations suggest that there are differences in the sensitivity of the hypothalamic-pituitary-thyroid axis and/or the peripheral deiodinases to glucocorticoids between fetal and adult animals and with changes in sex steroid concentrations in the adult (Ahlquist et al. 1989, Lisboa et al. 2001, Forhead et al. 2006). Certainly, in pregnant ewes, dexamethasone treatment has differential effects on deiodinase activity in fetal and maternal tissues during late gestation (Forhead et al. 2007).

\section{Mechanisms of dexamethasone action}

The mechanisms by which glucocorticoids enhance hepatic glycogen deposition and induce gluconeogenic enzyme activities in the liver and kidneys remain unknown. The hyperglycemia induced by dexamethasone may increase the availability of glucose molecules for glycogen synthesis. However, in fetal ovine liver, glycogen deposition depends on gluconeogenesis and the availability of gluconeogenic precursors, such as lactate and certain amino acids, rather than on the circulating concentration of glucose per se (Levitsky et al. 1988). In fetal sheep, the effects of cortisol on hepatic glycogen deposition and gluconeogenic enzyme activities in the fetal liver and kidney are known to be mediated, at least in part, by $\mathrm{T}_{3}$ (Forhead et al. 2003, Matthews et al. 2006). This may explain the differential effects of dexamethasone on G6Pase activity in fetal and adult liver in the current study, since plasma $\mathrm{T}_{3}$ concentrations rose in response to dexamethasone in the fetus but not in the mothers or non-pregnant ewes. Postnatally, glucocorticoids, thyroid hormones, and insulin all stimulate the activity of the phosphorylase responsible for activating glycogen synthase (Schwartz \& Rall 1973). Thyroid hormones 
and insulin also stimulate dephosphorylation of glycogen phosphorylase, which inactivates this enzyme and prevents glycogenolysis (Malbon \& Campbell 1984, Bollen \& Stalmans 1988). During maternal dexamethasone treatment, the increases in plasma dexamethasone, $\mathrm{T}_{3}$, and insulin in the fetus may act together to increase the hepatic deposition of glycogen by increasing its synthesis and reducing its breakdown. In contrast, in the dexamethasone-treated adults, the enhanced hepatic glycogen content is more likely to reflect increased glycogen synthesis alone as plasma $T_{3}$ and insulin concentrations were not raised in these circumstances. In summary, dexamethasone administration to sheep increases glycogen deposition in fetal and adult liver but probably by different mechanisms before and after birth. Dexamethasone also has differential effects on thyroid hormone status and on renal and hepatic G6Pase activity in fetal and adult sheep, which may have consequences for other endocrine and metabolic responses to glucocorticoid administration.

\section{Clinical relevance}

The current findings are directly relevant to the clinical management of threatened pre-term labor in women. The dexamethasone dosing regime used in the present study is the one recommended for human clinical use (NIH Consensus Development Conference 1995) and is known to lead to fetal plasma dexamethasone concentrations at the time of tissue collection within the range of values observed in human infants at delivery after maternal glucocorticoid administration (Dancis et al. 1980, Kream et al. 1983, Bennett et al. 1999, Jellyman et al. 2005a). Although tissue sensitivity to synthetic glucocorticoids may vary amongst animals (Stolte et al. 2006), dexamethasone crosses the placenta readily in both women and ewes and has a similar range of maturational effects on the fetus in these two species (Kream et al. 1983, Fowden et al. 1998, Bennett et al. 1999, Jellyman et al. 2005a). During pregnancy, the increases in hepatic glucogenic capacity induced by dexamethasone are likely to enhance the fetal and maternal glycemic responses to challenges, such as labor, delivery, and lactation that increase the demand for glucose. Consequently, the improved clinical outcome of preterm human infants treated antenatally with synthetic glucocorticoids may reflect, in part, an increased perinatal availability of glucose mediated via both direct fetal and indirect maternal actions of these hormones.

\section{Acknowledgements}

We would like to thank Sue Nicholls and Scott Gentle for their care of the animals. The work was part-funded by the Biotechnology and Biological Sciences Research Council, Tommy's, the Baby Charity, and the Gates Cambridge Trust (Scholarship for K L F). The authors declare that there is no conflict of interest that would prejudice the impartiality of this scientific work.

\section{References}

Ahlquist JAO, Franklyn JA, Ramsden DP \& Sheppard MC 1989 The influence of dexamethasone on serum thyrotrophin and thyrotrophin synthesis in the rat. Molecular and Cellular Endocrinology 64 55-61.

Barnes RJ, Comline RS \& Silver M 1978 Effect of cortisol on liver glycogen concentrations in hypophysectomized, adrenalectomized and normal foetal lambs during late or prolonged gestation. Journal of Physiology 275 $567-579$.

Bell ME, Wood CE \& Keller-Wood M 1991 Influence of reproductive state on pituitary-adrenal activity in the ewe. Domestic Animal Endocrinology 8 245-254.

Bennett L, Kozuma S, McGarrigle HH \& Hanson MA 1999 Temporal changes in fetal cardiovascular, behavioural, metabolic and endocrine responses to maternally administered dexamethasone in the late gestation fetal sheep. British Journal of Obstetrics and Gynaecology 106 331-339.

Bergman EN, Brockman RP \& Kaufman CF 1974 Glucose metabolism in ruminants: comparison of whole body turnover with production in the gut, liver and kidney. Federation Proceedings 33 1849-1854.

Bollen M \& Stalmans W 1988 The effect of the thyroid status on the activation of glycogen synthase in liver cells. Endocrinology 122 2915-2919.

Dancis J, Jansen V \& Levitz M 1980 Placental transfer of steroids: effects of binding to serum albumin and to placenta. American Journal of Physiology 238 E208-E213.

Dawkins MJR 1966 Biochemical aspects of developing function in newborn mammalian liver. British Medical Bulletin 22 27-33.

DeGroot LF \& Hoye EK 1976 Dexamethasone suppression of serum $T_{3}$ and $\mathrm{T}_{4}$. Journal of Clinical Endocrinology and Metabolism 42 976-978.

Epstein MF, Farrell PM, Sparks JW, Pepe G, Driscoll GG \& Chez RA 1977 Maternal betamethasone and fetal growth and development in the monkey. American Journal of Obstetrics and Gynecology 127 261-263.

Fletcher AJW, Goodfellow MR, Forhead AJ, Gardner DS, McGarrigle HHG, Fowden AL \& Giussani DA 2000 Low doses of dexamethasone suppress pituitary adrenal function but augment the glycaemic response to acute hypoxia in fetal sheep during late gestation. Pediatric Research 47 684-691.

Forhead AJ, Poore KR, Mapstone J \& Fowden AL 2003 Developmental regulation of hepatic and renal gluconeogenic enzymes by thyroid hormones in fetal sheep during late gestation. Journal of Physiology 548 941-947.

Forhead AJ, Curtis K, Kaptein E, Visser TJ \& Fowden AL 2006 Developmental control of iodothyronine deiodinases by cortisol in the ovine fetus and placenta near term. Endocrinology 14212.

Forhead AJ, Jellyman JK, Gardner DS, Giussani DA, Kaptein E, Visser TJ \& Fowden AL 2007 Differential effects of maternal dexamethasone treatment on circulating thyroid hormone concentrations and tissue deiodinase activity in the pregnant ewe and fetus. Endocrinology In Press.

Fowden AL \& Silver M 1995 The effects of thyroid hormones on oxygen and glucose metabolism in the sheep fetus during late gestation. Journal of Physiology 482 203-213.

Fowden AL \& Forhead AJ 2004 Endocrine mechanisms of intrauterine programming. Reproduction 127 515-526.

Fowden AL, Mijovic J \& Silver M 1993 The effects of cortisol on hepatic and renal gluconeogenic enzyme activities in the sheep fetus during late gestation. Journal of Endocrinology 137 213-222.

Fowden AL, Li J \& Forhead AJ 1998 Glucocortiocids and the preparation for life after birth; are there long term consequences of the life insurance? Proceedings of the Nutrition Society 57 113-122.

Fowden AL, Ousey JC \& Forhead AJ 2001 Comparative aspects of prepartum maturation; provision of nutrients. Pferdeheilkunde 17 653-658.

Jellyman JK, Gardner DS, Edwards CMB, Fowden AL \& Giussani DA 2005a Fetal cardiovascular, metabolic and endocrine responses to acute hypoxaemia during and following maternal treatment with dexamethasone in sheep. Journal of Physiology 567 673-688.

Jellyman JK, Gardner DS, Edwards CMB, Fowden AL \& Giussani DA $2005 b$ The effects of pregnancy on the cardiovascular response to acute systemic isocapnic hypoxia in conscious sheep. British Journal of Obstetrics and Gynaecology 112 889-896. 
Keller-Wood ME, Silbiger J \& Wood CE 1988 Progesterone attenuates the inhibition of adrenocorticotropin responses by cortisol in non pregnant ewes. Endocrinology 123 647-651.

Klepac R 1985 Effect of dexamethasone on glycogen deposition in pregnant rats and their fetuses. Experimental and Clinical Endocrinology 86 305-309.

Kream J, Mulay S, Fukushima DK \& Solomon S 1983 Determination of plasma dexamethasone in the mother and the newborn after administration of the hormone in a clinical trial. Journal of Clinical Endocrinology and Metabolism 56 127-133.

Levitsky LL, Paton JB \& Fisher DE 1988 Precursors to glycogen in ovine fetuses. American Journal of Physiology 255 E743-E747.

Liggins GC 1994 The role of cortisol in preparing the fetus for birth. Reproduction, Fertility, and Development 6 141-150.

Lisboa PC, Curty FH, Moreira RM, Oliveira KJ \& Pazos-Moura CC 2001 Sex steroids and rat anterior pituitary and liver iodothyronine deiodinase activities. Hormone and Metabolism Research 33 532-535.

Malbon CC \& Campbell R 1984 Thyroid hormones regulate hepatic glycogen synthase. Endocrinology 115 681-686.

Matthews PA, Fowden AL \& Forhead AJ 2006 Role of thyroid hormones in the deposition of hepatic glycogen in fetal sheep near term. Early Human Development 82 633-634.

Mitsuma T \& Nogimori T 1982 Effects of dexamethasone on the hypothalamic-pituitary-thyroid axis in rats. Acta Endocrinologica 100 51-56.

NIH Consensus Development Conference 1995 Effects of corticosteroid for fetal maturation on perinatal outcomes. Journal of the American Medical Association 273 413-418.

Osathanondh R, Chopra IJ \& Tulchinsky D 1978 Effects of dexamethasone on fetal and maternal thyroxine, triiodothyronine, reverse triiodothyronine and thyrotropin levels. Journal of Clinical Endocrinology and Metabolism 47 1236-1249.

Robinson PM, Comline RS, Fowden AL \& Silver M 1983 Adrenal cortex of fetal lamb: changes after hypophysectomy and effects of synacthen on cytoarchitecture and secretory activity. Quarterly Journal of Experimental Physiology 68 15-27.

Roehrig KL \& Allred JB 1974 Direct enzymatic procedure for the determination of liver glycogen. Analytical Biochemistry 58 414-421.

Schwartz AL \& Rall TW 1973 Hormonal regulation of glycogen metabolism in neonatal rat liver. Biochemical Journal 134 985-993.

Shelley HJ 1961 Glycogen reserves and their changes at birth and in anoxia. British Medical Bulletin 17 137-143.

Stolte EH, Kemenade BM, Savelkoul HF \& Flik G 2006 Evolution of glucocorticoid receptors with different glucocorticoid sensitivity. Journal of Endocrinology 190 17-28.

Thomas AL, Krane EJ \& Nathanielsz PW 1978 Changes in the fetal thyroid axis after induction of premature parturition by low dose continuous intravascular cortisol infusion to fetal sheep at 130 days of gestation. Endocrinology 103 17-23.

Trahair JT \& Sangild P 1997 Systemic and luminal influences on the perinatal development of the gut. Equine Veterinary Journal 24 40-50.

Tye LM \& Burton AP 1980 Glycogen deposition in fetal mouse tissues and the effect of dexamethasone. Biology of the Neonate 38 265-269.

Received in final form 17 September 2006 Accepted 5 October 2006 